\title{
Manufacturing System Design Based on Axiomatic Design: Case of Assembly Line
}

\author{
Triki Hager $^{1}$ (D), Hachicha Wafik ${ }^{2,3}$ (iD), Masmoudi Faouzi² \\ ${ }^{1}$ Engineering School of Sfax (Tunisia) \\ ${ }^{2}$ Unit of Mechanic, Modelling and Production (U2MP) (Tunisia) \\ ${ }^{3}$ Department of Industrial Management, Higher Institute of Industrial Management of Sfax (Tunisia) \\ HagerTriki@yahoo.fr, wafik.hachicha@yahoo.fr,faouzi.masmoudi@enis.rnu.tn
}

Received: March 2013

Accepted: March 2017

\section{Abstract:}

Purpose: In this paper, a combined Production Line Design (PLD) process which includes many design aspects is presented, developed and validated.

Design/methodology/approach: The PLD process is based on the SADT (Structured Analysis and Design Technique) diagram and the Axiomatic Design (AD) method.

Findings: The results of the validation indicated that the production line designed by this process is outperformed the initial line of the company.

Practical implications: For a purpose of validation, this proposed process has been applied in a manufacturing company and it has been validated by simulation.

Originality/value: Recently, the problems of production line design (PLD) have attracted the attention of many researchers. However, only a few studies have treated the PLD which includes all design aspects. In this work, a combined PLD porcess is presented. It should be noted that the proposed process is simple and effective.

Keywords: production line design, assembly line, axiomatic design, SADT, configuration, performance 


\section{Introduction}

Facing competition, the most rapid emergence of new products, changing consumer fashions and globalisation, the entreprises are forced to call into question the efficiency of their design methods to keep their competitive edge and ensure their survival. The production system design is responsible for the selection, implantation and provision of resources. Furthermore, designing a production system to achieve a set of strategic objectives involves making a series of complex decisions over time (Hayes \& Wheelwright, 1979). For this reason, the design of production systems has always been an important problem in industrial engineering (Dolgui, 2001). Nowadays, production systems are characterized by short lifecycle time of products and production systems, high level of automation, emergence of new manufacturing equipment and technologies, and high investment for building modern production lines (Rekiek, Dolgui, Delchambre \& Bratcu, 2002). For large-scale enterprises, configuration of new production line is likely to need many production functions. Furthermore, a long design period is required (Essafi, Delorme, Dolgui \& Guschinskaya, 2009). Consequently, the search of an optimal line configuration which minimizes line investment cost is crucial (Dolgui \& Ihnatsenka, 2009). In fact, assembly line design is an important part of the production system (Kuo \& Yang, 2011). Indeed, our objective is to find a truthful method of production line design to reach many objectives.

\subsection{Related Works}

In recent years, many studies have dealt with different facets of production line design to reach several objectives through several methods.

Graves and Lamar (1983) have developed an integer programming cost-based model to the problem of automated system design. Their aim has been to determine the type and the number of stations, and the operations assigned to these stations. Lenz, Rubinovitz and Bukchin (1993) have described a heuristic approach for designing and balancing of a robotic assembly line. The authors presented a recommendation of the optimal set of heuristic rules which is made based on results of extensive testing of this problem with a variety of assembly line problems. McMullen and Frazier (1998) have used a "Simulated Annealing" (SA) to solve assembly line balancing problem to minimize the design cost associated with both labour requirements and equipment requirements. Asar and Andrew (2001) have presented a Knoweledge Based Design Methodology (KBDM) which can be applied on automated and manual assembly lines that produce single, multi and mixed product assembly lines with either deterministic operation times or stochastic operation times. 
Guschinskaya, Dolgui, Guschinsky and Levin (2007) have proposed a heuristic multi-start decomposition approach to get an optimal design of serial machining line. Dolgui and Ihnatsenka (2009) have used the branch and bound algorithm for a transfer line design. Their goal is to perform each operation one time and to minimize the total cost of line while all the precedence, cycle time, and compatibility constraints are satisfied. Xu, Ko, Cochran and Jung (2012) have presented a methodology based on linear models that can be used to integrate ergonomic measures of upper extremities into an assembly line design problem. Nourmohammadia, Zandiehb and Tavakkoli-Moghaddamca (2013) have proposed a new population-based evolutionary algorithm, namely Imperialist Competitive Algorithm (ICA) to address the U-type assembly line design problem. The aim of this approach is to minimize the line efficiency and the variation of workload.

The literature has included a large variety of other reviews that are related to the production lines design problems (balancing, ergonomic measures, configuration etc.) and many methods to solve these problems such as Progressive Approach (PA) (Lan, 2007), A hierarchical Fuzzy Inference System (FIS) (Nada, Elmaraghy \& Elmaraghy, 2006), swarm optimization (PSO) algorithm (Kuo et al., 2011), moderately robust optimization approach (Nazarian \& Ko, 2013). But, each studied problem represents one step of production line design. In fact, these studies have presented limits to the application of their methods due to the absence of a global process for the production lines design. This process takes account of all steps of production line design (problems) which undergo changes in the order of treatment according to the line type.

This paper introduces a new model of a global process for the production lines design for assembly lines semi-automatics that produce multiple products. This process combines AD method and SADT to generate several feasible and potentially profitable designs. The outline of the rest of this paper is organized as follows: Section 2 presents an AD method and their key concept detected in the literature. Section 3 explains the proposed conceptual design which is decomposed by the SADT diagram and the hierarchical decomposition. Section 4 deals with a case study of a manufacturing assembly line design with the proposed design process. Finally, the main conclusions of the study are presented in Section 5. 


\section{AD Method and Their Key Concepts}

\subsection{AD Method}

The AD method has been created about 10 years before and conceived as a systematic model for engineering education and practice (Suh, 1990). AD is a structured design method created to improve design activities by establishing criteria on which potential designs may be evaluated, and tools for implementing those criteria (Suh, 2001). The principles of AD present better design solutions in the shortest time as they provide a systematic research process in a design space which becomes complicated with customer requires (Kulak, Cebi \& Kahraman, 2010). Also, AD constitutes a formalized methodology that can be used to represent a variety of design problems (National Academy of Engineering, 2002), especially in the design processes of product, production systems, software and many others design problems.

In the last 20 years, many reviews have appeared in the literature concerning the domains of $\mathrm{AD}$ which has a usefulness of basic principles for analyzing, comparing, and selecting solutions. First, Suh (1990) has introduced AD theory and principles. Then, he has applied this approach in various fields such as structural design in structures of civil engineering (Albano \& Suh, 1992) and artificial skin design (Gebala \& Suh, 1992). Afterward, he proposed AD method in order to make decisions during the design stage of product and process development (Suh, 1995) affecting product quality and process productivity.

Arinez and Cochran (2000) have defined an equipment design approach based on axiomatic design. This approach is used to analyze and decompose the requirement of equipment design into design parameters.

Lindkvist and Soderberk (2003) have developed a software tool based on the AD to evaluate and analyze the design of assemblies with respect to degree of geometrical coupling and robustness. Houshmand and Jamshidnezhad (2006) have developed an axiomatic design modeling of lean production system design. Schnetzler, Sennheiser, and Schonsleben (2007) have presented an AD method to support supply chain management with information management and information technology. Hachicha, Masmoudi and Haddar (2008) have combined the axiomatic design and experimental design to cellular manufacturing system design. The authors have tried to generate several feasible and profitable designs.

Taha, Soewardi and Dawal (2014) have explored the ergonomics design parameters of the virtual environment to minimize some negative side effects. The authors have applied the axiomatic design principles to identify and define customers' preference in this type of environment. In fact, $\mathrm{AD}$ has 
been applied in many examples of design of manufacturing systems summarized in the Figure 1. In the litterature, the $\mathrm{AD}$ has never been applied in the assembly line design problem, although it is very difficult problem. For this reason, this work introduces the use of AD in the design of assembly line. The aim of this work is to provide a new foundation for describing, determining and rationalizing the design of any new assembly line.

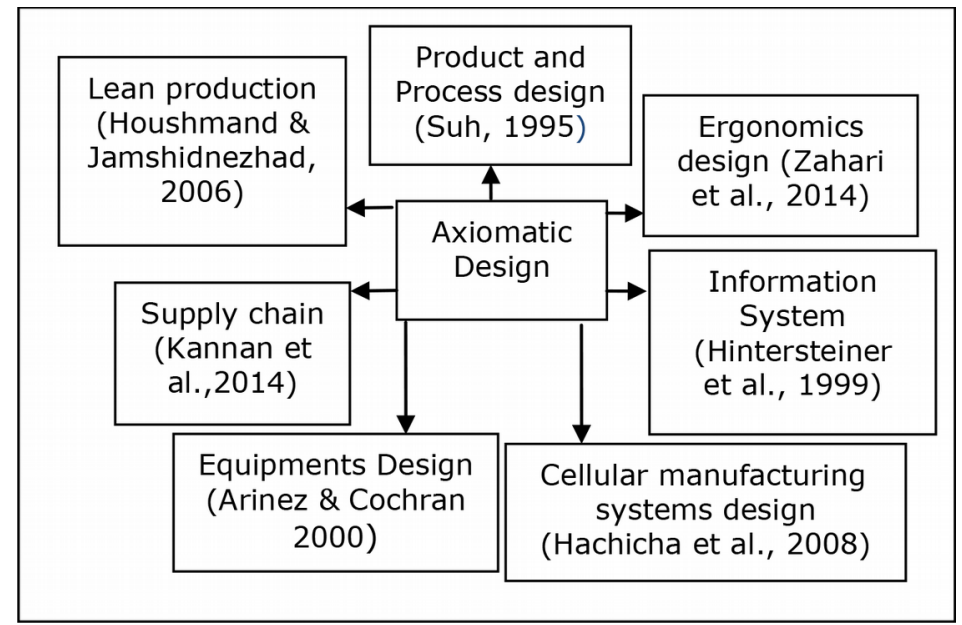

Figure 1. The domains of axiomatic design application in manufacturing system

\subsection{Key Concepts of Axiomatic Design}

In industrial practice, engineers tend to tackle difficult problems by decomposing them into sub-problems and attempting to maintain independent solutions for these smaller problems (Hachicha et al., 2008). This requires an effective approach that gives guidelines for the decomposition of difficult problems and independent mappings between problems and solutions. AD approach provides a good decomposition mechanism.

AD defines design as the creation of synthesized solutions in the form of products, processes or systems that satisfy the identified needs through mapping between Functional Requirements (FRs) and Design Parameters (DPs) (Suh, 1990). The Functional Requirements (FRs) represent the purposes of the design. FRs are defined in the functional domain in order to satisfy the needs which are defined in the customer domain. The DPs express how to satisfy the FRs. DPs are formed in the physical domain to satisfy the FRs. The design domains are exhibited in Figure 2. As depicted in Figure 2, the needs' design is described in the customer domain by the customer need vector, $\{\mathrm{CN}\}$; in the functional domain by the functional requirement vector, $\{\mathrm{FR}\}$; in the physical domain, by the design parameter vector, $\{\mathrm{DP}\}$; and in the process domain by the process variable vector, $\{\mathrm{PV}\}$. The customer needs have to be mapped to the 
functional domain where these needs are transformed into a set of FRs, which by definition, are independent. Moreover, a design should be defined with the minimum amount of information in each domain (Ferrer, Rios, \& Ciur, 2009; Suh, 2001). Not only will Functional Requirements be defined for the new design, but also constraints will appear as a result of translating customer needs to FRs. Constraints that are placed above all domains, must be respected during the entire design process. Then, the FRs are mapped to the physical domain and the DPs are mapped to the process domain in terms of PVs. The main goal of $\mathrm{AD}$ is to establish a scientific basis for design and to improve design activities by providing the designer with a theoretical foundation based on logical and rational thought processes and tools (Suh, 1990, 2001).

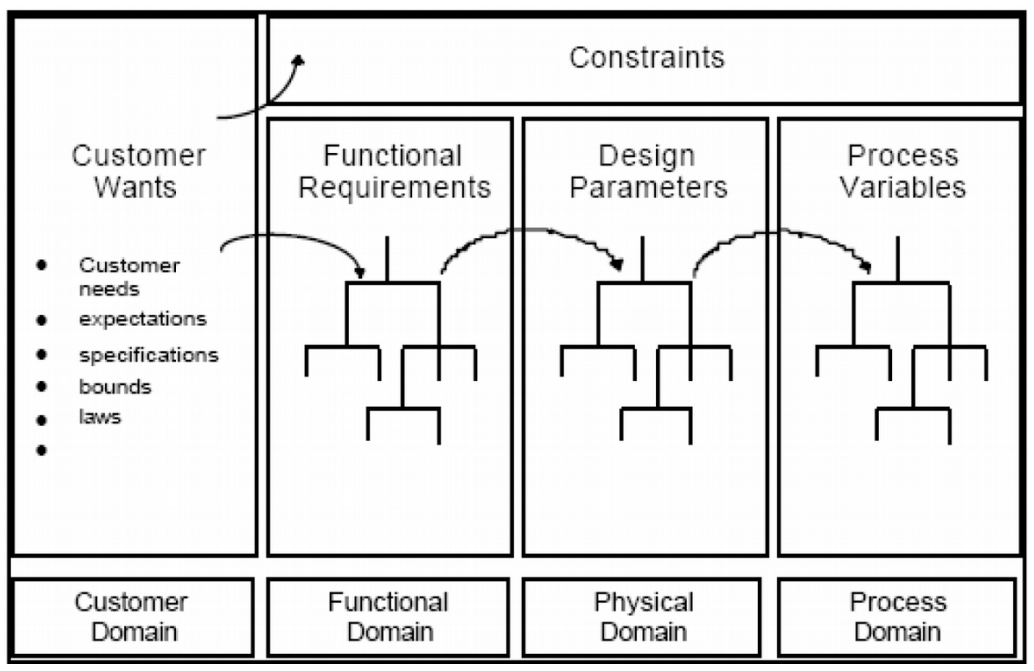

Figure 2. All design can be represented in four domains (Suh, 1990)

In accomplishing this goal, the designer has to compose the problem in hierarchies in the functional, physical and process domains. The construction of the hierarchy will be done by zigzagging between the domains. The zigzagging must be located between two domains. After defining the FR of the top level, a design concept has to be created. The design decision is made at the left to right legs of the zigzagging path (Suh, 2001). Several examples of zigzag decomposition can be found in Suh (1990, 2001). An elemental zigzagging cycle is shown in Figure 3. 


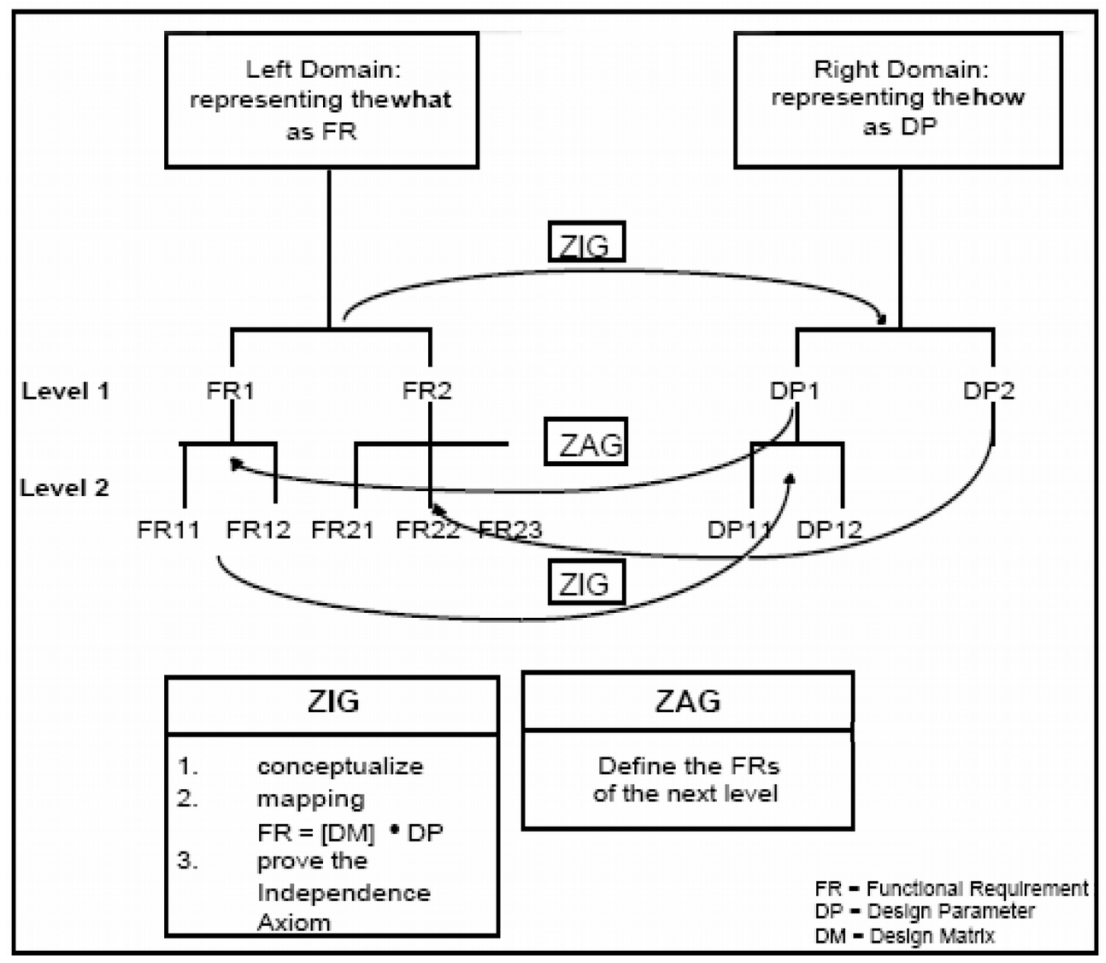

Figure 3. Zigzagging between the domains to develop the Hierarchy (Suh, 2001)

In order for mapping to be satisfied between domains, two axioms must be respected (Suh,1990):

Axiom 1: The Independence Axiom

Maintains the Independence of the FRs

Axiom 2: The Information Axiom

Minimizes the Information Content of the design

Furthermore, the fact that axioms can be generalized allows the $\mathrm{AD}$ to be effective and powerful in different design areas (Kulak et al., 2010).

Using mathematical terminology, these mappings are denoted by Equation (1):

$$
\left\{F R_{s}\right\}=[D M]\left\{D P_{s}\right\}
$$

Where $[D M]$ is the design matrix for design conceptual. The elements of the design matrix indicate the effects of changes of the DPs on the FRs (Tate, 1999). It is necessary to ensure that the design matrix as established satisfies the axioms of AD principles (Suh, 1990). In order to satisfy the independence axiom, Suh (2001) has suggested that the design matrix must be the diagonal matrix or triangular matrix. If the 
design matrix is diagonal, the design will be uncoupled, if the design matrix is triangular, the design solution will be called as decoupled. Otherwise, the design is named as coupled (Suh, 1990).

\section{The Proposed Conceptual Design}

The proposed process for assembly line design is decomposed into three steps. Firstly, a SADT diagram is developed. Secondly, the hierarchical decompositions of FRs and DPs are deduced from SADT diagram. Finally, the matrices designs are built.

\subsection{Step 1: SADT Diagram}

The first step of the proposed process is the SADT diagram (Structured Analysis and Design Technique). It is an American method which has been introduced by Doug Ross since 1977. The SADT is used to model the decisions, actions, and activities of a manufacturing system in a structured graphical form. It presents a powerful tool of analysis and development for the manufacturing enterprise. In this paper, the SADT method is used to assure obtaining diagonal matrix. That is the satisfaction of the axiom of the independence and the axiom of information into the application of the $\mathrm{AD}$ method. The development of the diagram SADT started by the first activity box A-0 of SADT diagram as displayed in Figure 4 . The inputs are exhibited as arrows entering the left side of the A-0, while the outputs are shown as outgoing arrows on the right side of the activity box. The controls are shown as arrows entering the top of the A0 , and mechanisms or means used to carry out A-0 are shown as arrows entering from the bottom of the box. The inputs, outputs, controls and mechanisms are referred to as concepts.

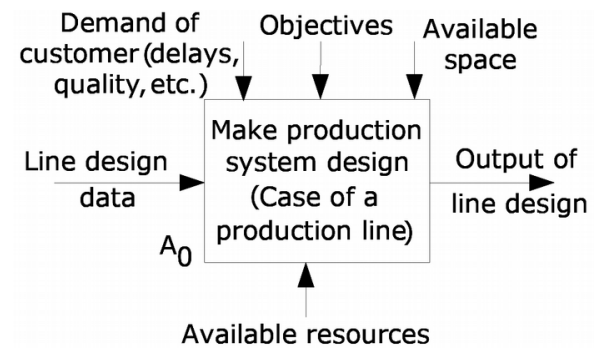

Figure 4. Assembly line design (level $\left.A_{0}\right)$

The concepts of diagram SADT are based on many hypotheses and a specific problematic on the line which will be designed, such as: 


\section{Hypotheses:}

- The line type is a semi automatic

- A multi product is treated in this line

- Each machine (resource) type necessarily has the ability to perform any assembly task.

\section{Problematic:}

How to select resources (available in the market) to implant them in an available space (shop) to reach many objectives (in terms of performance)

According to these hypotheses and this problematic mentioned above, the concepts of A- 0 are built as follows:

Inputs of A-0: Data of the assembly line design:

- Operations of transformation

- Matrix of impact

- Nature of resources

Outputs of A-O: Outputs of line design are:

Better assembly line design and workload smoothness between stations for desired cycle time.

The point of control:

- Demand of customer

- Available space when the resources will be implanted

- The objectives to reach

The means used to perform A-O: Available resources in the market:

A strategy to organize the development of SADT diagram is the notion of the hierarchical decomposition of activities. The decomposition of A-0 is performed inside this activity into smaller activities. This hierarchical structure keeps the scope of the model designed within the boundaries represented by the proposed hypothesis. These multi-level activities progressively expose more details at each level. Each level is simple to understand in comparison to the complexity of the whole model.

This assembly line design problem involves constructing five distinct classes of design problems such as: Balancing (Scholl, Fliedner \& Boysen, 2011), configuration (Nourmohammadi et al., 2013), selection of 
resources (Miralles, García-Sabater, Andrés \& Cardós, 2008), transport (Asar \& Andrew, 2001) etc. Then the activity A- 0 is decomposed in five small activities as it is indicated in Figure 5.

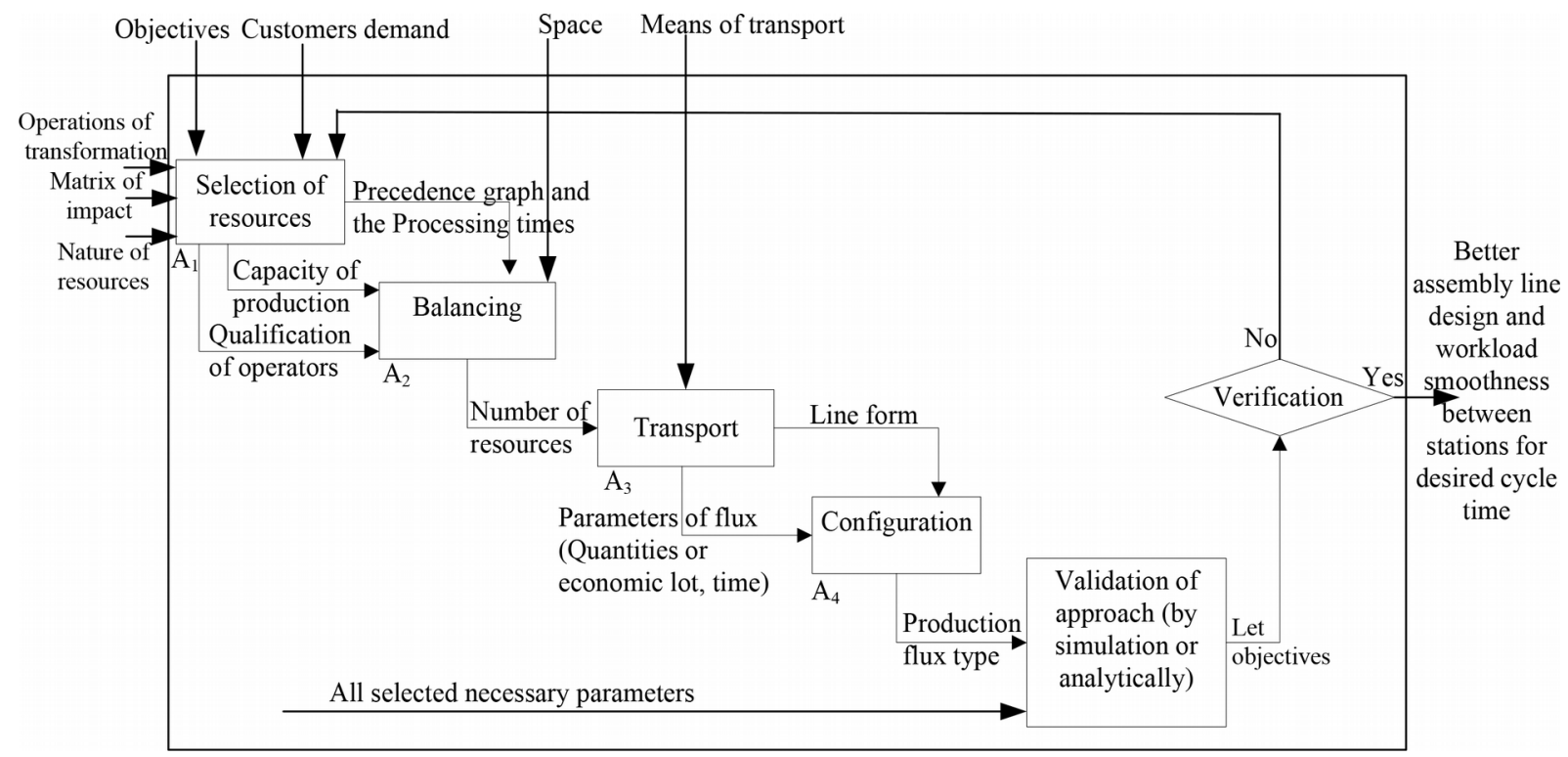

Figure 5. Activity $A_{0}$

Each activity is decomposed into a set of other activities to detail each design problem as indicated in the following Figures 6, 7, 8, 9 and 10.

The resource selection is decomposed into two problems: the selection of equipment and the selection of human resources as indicated in Figure 6.

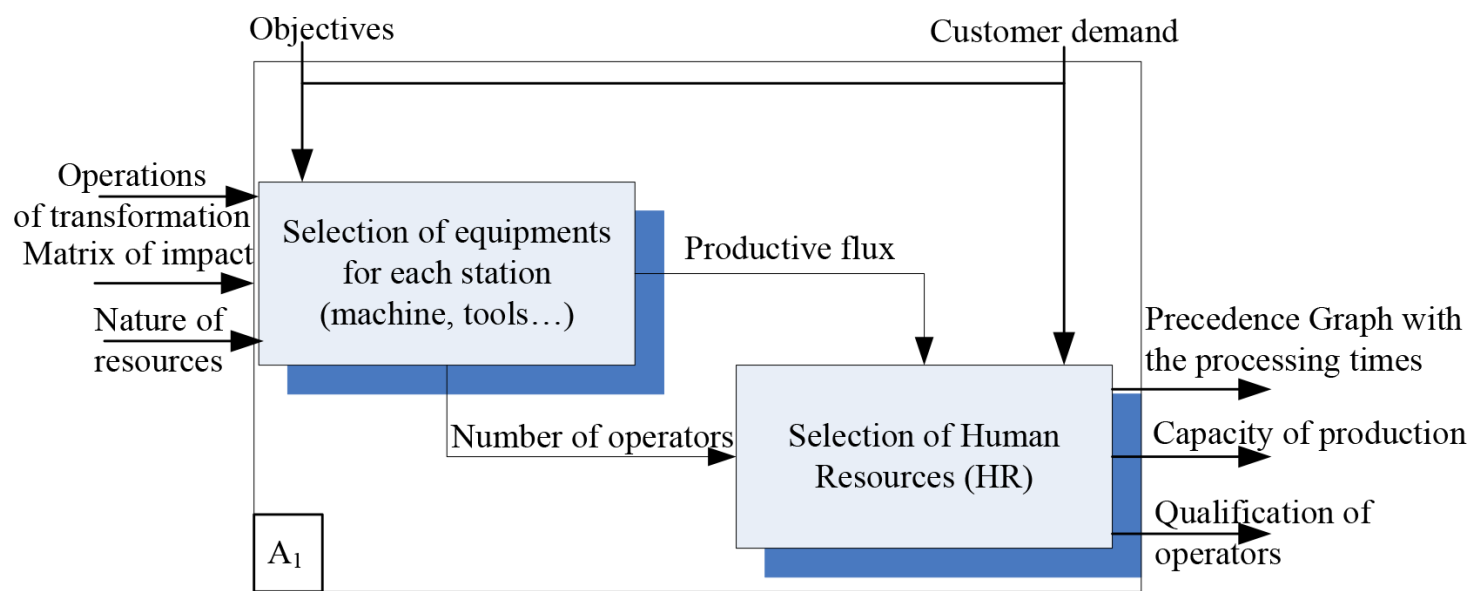

Figure 6. Activity $A_{1}$ : Resources selection 
The balancing is the problem of partition of operations to stations, of sizing buffer between and selection of transfer between stations as shown in the Figure 7.

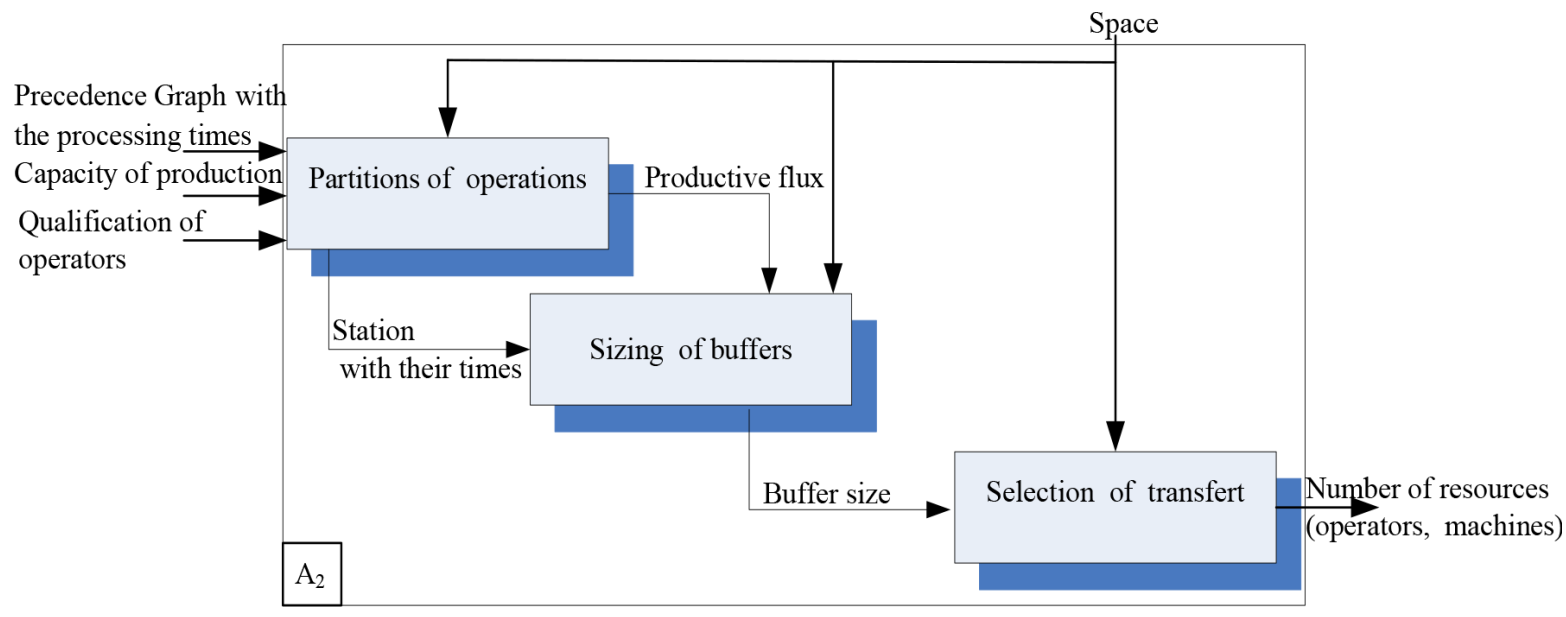

Figure 7. Activity $A_{2}$ : Balancing

In order to solve the transport problem, the means of transport have to be identified and their parameters have to be determined as indicated in Figure 8.

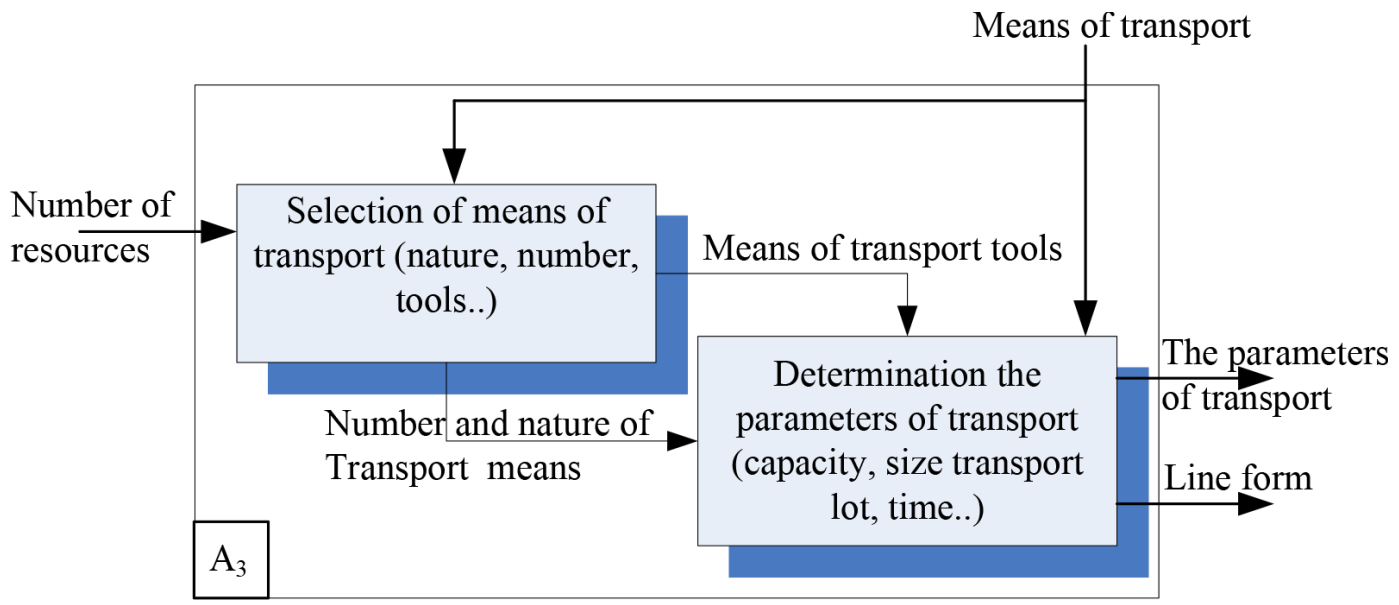

Figure 8. Activity $A_{3}$ : Transport

According to the parameters of transport and the line form, the final configuration of line can be determined by new implantations and some modifications of organisation as shown in Figure 9. 


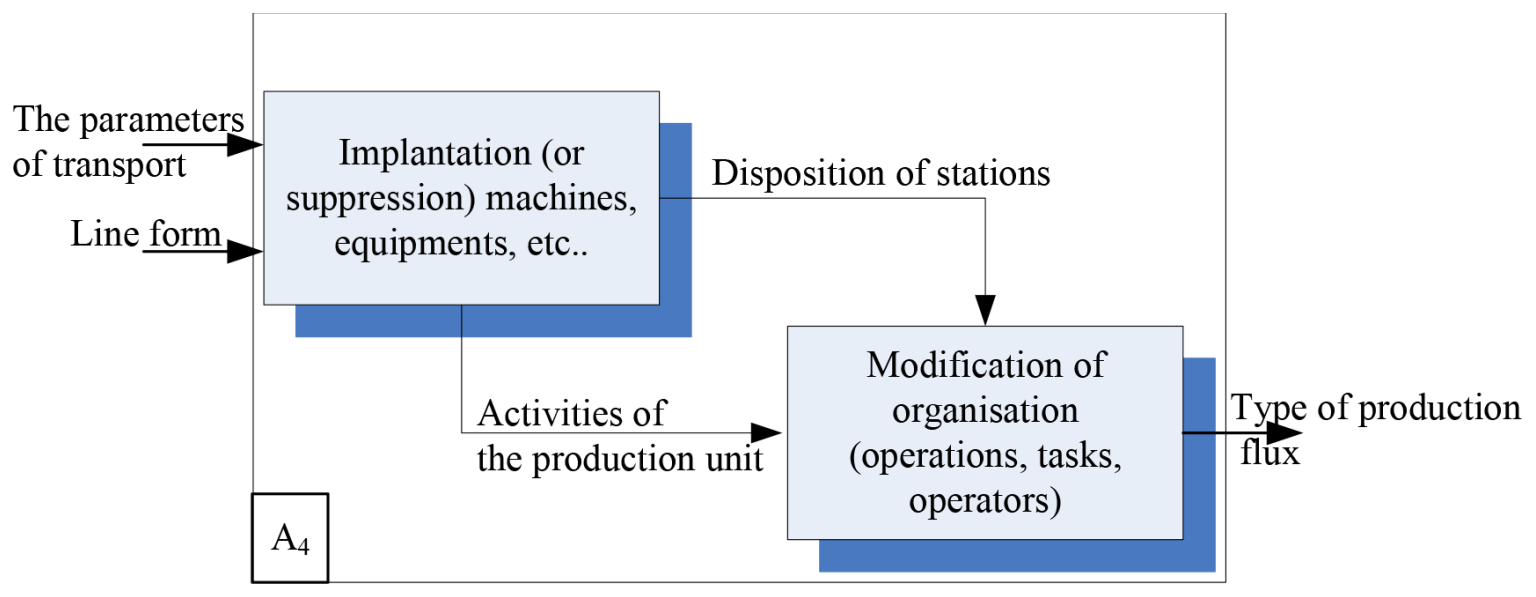

Figure 9. Activity $A_{4}$ : Configuration of line

The last activity demonstrates the steps of validation of the proposed process. The validation consists in the modelling and the simulation of the assembly line (founded by computer's program) to extricate the indicators of performances as indicated in Figure 10.

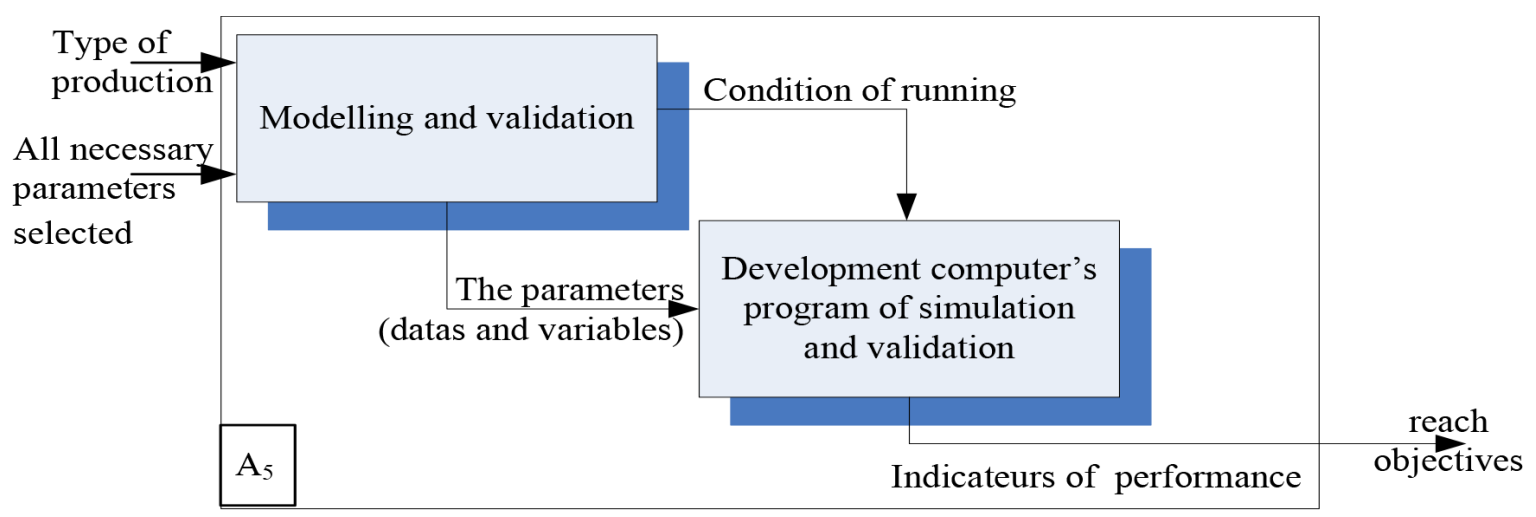

Figure 10 . Activity $A_{5}$ : Validation (by simulation)

\subsection{Step 2: Hierarchical Decomposition}

According to the SADT Diagram and the graphic representation of SADT diagram, the hierarchical decompositions of FRs and DPs can be built as shown in Figures 11 and 12 respectively. The activities consist in the FRs $\left(A_{i}=F R_{i}\right)$ and the interconnections between the activities form the DPs. 


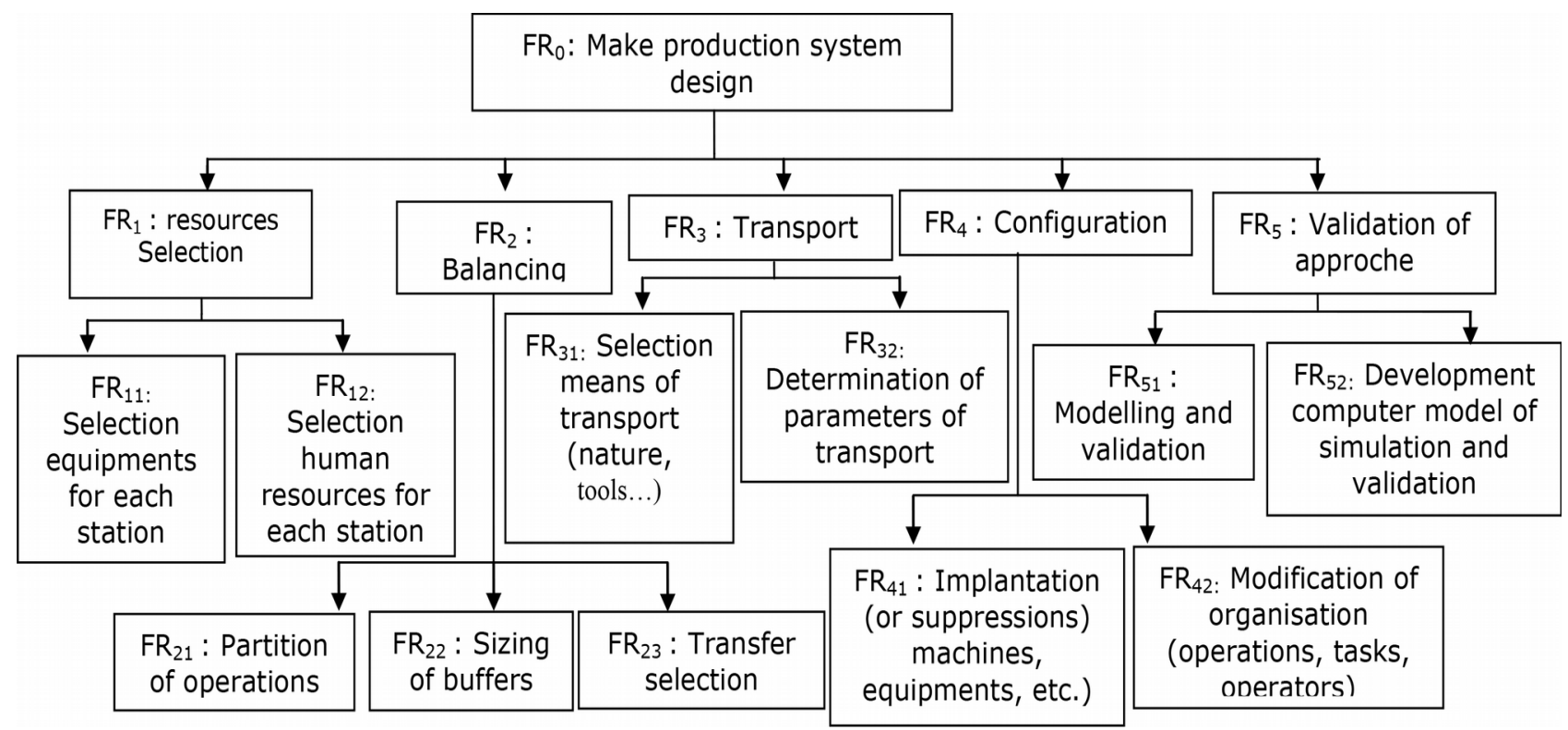

Figure 11. The hierarchical decomposition of FRs

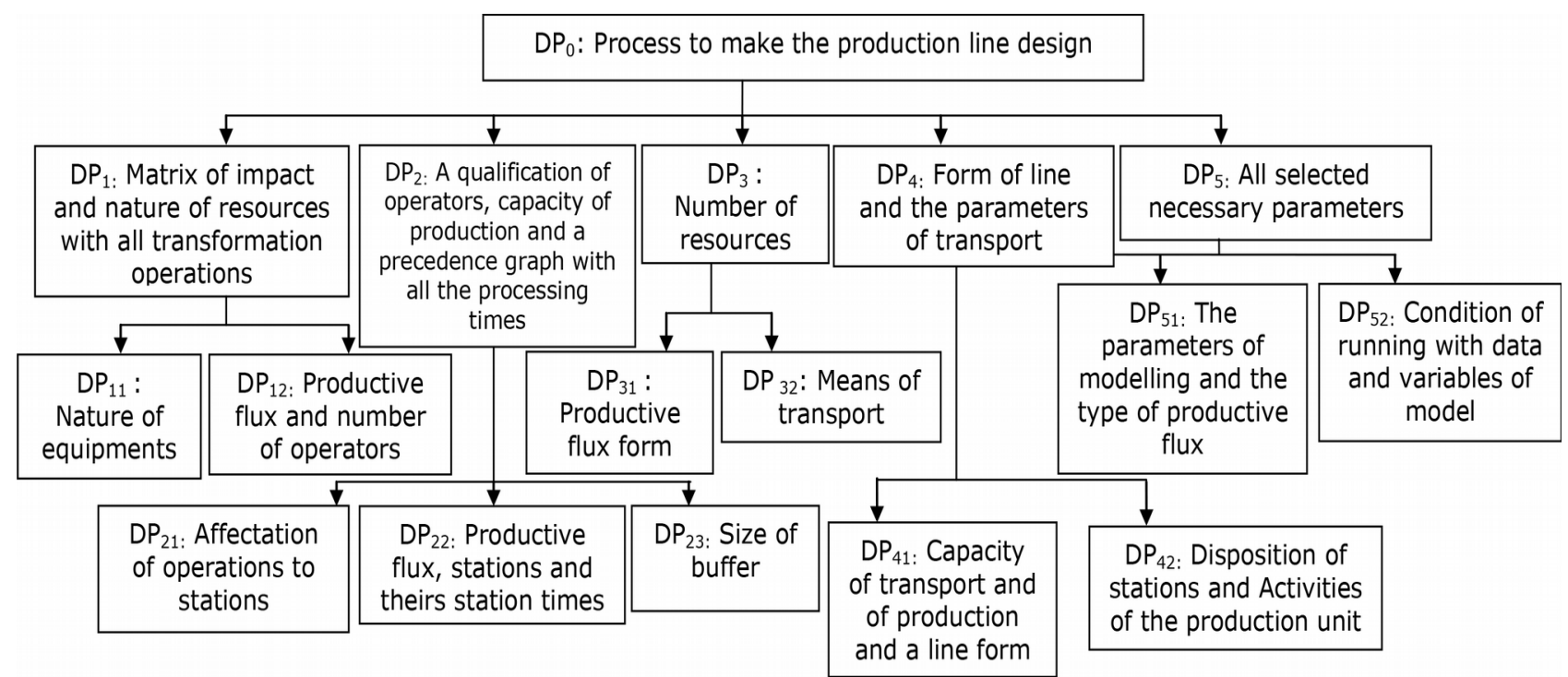

Figure 12. The hierarchical decomposition of Dps

\subsection{Step 3: Matrices Design}

To maintain the independence axiom, the design matrix must be either diagonal/uncoupled or triangular/decoupled (Suh, 1990, 2001). According to SADT diagram and the hierarchical decompositions of FRs and DPs, the design matrices are built as follow:

The design Equation (2) describing the relationship between FRs and DPs at the first level is given by: 


$$
\left\{\begin{array}{l}
\mathrm{FR}_{1} \\
\mathrm{FR}_{2} \\
\mathrm{FR}_{3} \\
\mathrm{FR}_{4} \\
\mathrm{FR}_{5}
\end{array}\right\}=\left(\begin{array}{ccccc}
\mathrm{X} & 0 & 0 & 0 & 0 \\
\mathrm{X} X & 0 & 0 & 0 \\
\mathrm{X} X \mathrm{X} & 0 & 0 \\
\mathrm{X} X \mathrm{X} X & 0 \\
\mathrm{X} X \mathrm{X} & \mathrm{X} & \mathrm{X}
\end{array}\right\}\left\{\begin{array}{l}
\mathrm{DP}_{1} \\
\mathrm{DP}_{2} \\
\mathrm{DP}_{3} \\
\mathrm{DP}_{4} \\
\mathrm{DP}_{5}
\end{array}\right\}
$$

The symbol «X» signifies a strong relationship between the FRs and DPs. The value of «X» is non-zero. The equation presents a decoupled design or lower triangular design matrix where each FR is satisfied by a DP. The design obtained is acceptable.

The design matrices of level (2) are the following Equations (3), (4), (5), (6) and (7)

$$
\begin{aligned}
& \left\{\begin{array}{l}
\mathrm{FR}_{11} \\
\mathrm{FR}_{12}
\end{array}\right\}=\left(\begin{array}{ll}
\mathrm{X} & 0 \\
\mathrm{X} & \mathrm{X}
\end{array}\right\}\left\{\begin{array}{l}
\mathrm{DP}_{11} \\
\mathrm{DP}_{12}
\end{array}\right\} \\
& \left\{\begin{array}{l}
\mathrm{FR}_{21} \\
\mathrm{FR}_{22} \\
\mathrm{FR}_{23}
\end{array}\right\}=\left(\begin{array}{lll}
\mathrm{X} & 0 & 0 \\
\mathrm{X} & \mathrm{X} & 0 \\
\mathrm{X} & \mathrm{X} & \mathrm{X}
\end{array}\right\}\left\{\begin{array}{l}
\mathrm{DP}_{21} \\
\mathrm{DP}_{22} \\
\mathrm{DP}_{23}
\end{array}\right\} \\
& \left\{\begin{array}{l}
\mathrm{FR}_{31} \\
\mathrm{FR}_{32}
\end{array}\right\}=\left(\begin{array}{ll}
\mathrm{X} & 0 \\
\mathrm{X} & \mathrm{X}
\end{array}\right\}\left\{\begin{array}{l}
\mathrm{DP}_{31} \\
\mathrm{DP}_{32}
\end{array}\right\} \\
& \left\{\begin{array}{l}
\mathrm{FR}_{41} \\
\mathrm{FR}_{42}
\end{array}\right\}=\left(\begin{array}{ll}
\mathrm{X} & 0 \\
\mathrm{X} & \mathrm{X}
\end{array}\right\}\left\{\begin{array}{l}
\mathrm{DP}_{41} \\
\mathrm{DP}_{42}
\end{array}\right\} \\
& \left\{\begin{array}{l}
\mathrm{FR}_{51} \\
\mathrm{FR}_{52}
\end{array}\right\}=\left(\begin{array}{ll}
\mathrm{X} & 0 \\
\mathrm{X} & \mathrm{X}
\end{array}\right\}\left\{\begin{array}{l}
\mathrm{DP}_{51} \\
\mathrm{DP}_{52}
\end{array}\right\}
\end{aligned}
$$

The design matrix presented in Equations (3), (4), (5), (6) and (7) for the second level shows a decoupled design. It is an acceptable design at the second level where all elements are independent each other. Then each design activity (FR-DP) is formed without affecting the others. This affirms the satisfaction of the two axioms. 


\section{Case Study: Design of an Assembly Line Manufacturing System}

A proposed process is applied in a real industrial example that verifies the proposed hypotheses. The example consists in an assembly line of jacket of the DIADEM society (http://www.made-intunisia.net $/$ vitrine $/ 2$ infos generales.php?tc1 $=1 \mathrm{KmSmKiY}$ ) that is a confection manufacturing company. A semi automatic line of multiple products (several shapes of jacket) is studied in this company.

The validation is based on the comparison between the performance indicators of the proposed process of design and the performance indicators of this real assembly line. The application of the design process on assembly line of jacket is as follows:

(All data figured in this study are taken from the technical manual of this company.)

\subsection{FR1: Resources Selection}

DP1: Nature of resources with all transformation operations

- Transformation operations

The execution operations are presented in Table 2.

- Nature of resources

The execution of transformation operations needs operators and machines.

FR11: Selection equipments for each station

- DP11: Nature of equipments

The workshop needs five types of machines as indicated in Table 1.

\begin{tabular}{|c|c|}
\hline Type of machines & Designation \\
\hline Machine of serging & M1 \\
\hline Machine simple stitcher & M2 \\
\hline Machine of hem & M3 \\
\hline Iron to iron & M4 \\
\hline Pimply & M5 \\
\hline
\end{tabular}

Table 1. Type of machines 
FR12: Human resources selection for each station

- DP12: Number of operators

This workshop of confection works with two lines that have common machines. In fact, the capacity of operations $7,8,27,34,35,36$ is very high which can work for both lines at the same time. In order to balance only one line, the time of these operations will be multiplied by two. Since each operator performs some operations, the initial number of operators is 22 operators and the number of machines is 19 according to the Table 2 .

\begin{tabular}{|c|c|c|c|c|c|}
\hline $\mathbf{N}^{\circ}$ & Unit operations & $\begin{array}{l}\text { Operation } \\
\text { time (in min.) }\end{array}$ & $\begin{array}{c}\text { Number of } \\
\text { operators }\end{array}$ & Machines & $\begin{array}{l}\text { Occupation rate } \\
\text { of operation }\end{array}$ \\
\hline 1 & To close crowbar & 2 & \multirow{2}{*}{1} & \multirow{2}{*}{ M2 } & $20 \%$ \\
\hline 2 & Slanted pose & 1 & & & $10 \%$ \\
\hline 3 & Preparation of height & 2 & 1 & M2 & $20 \%$ \\
\hline 4 & Mounting of size + bottom pocket & 1.5 & \multirow{3}{*}{1} & \multirow{3}{*}{ M2 } & $15 \%$ \\
\hline 5 & Tackling pocket & 4 & & & $40 \%$ \\
\hline 6 & Close’s pocket & 3 & & & $30 \%$ \\
\hline 7 & Surjet melts pocket & 4 & \multirow{2}{*}{1} & \multirow{2}{*}{ M1 } & $40 \%$ \\
\hline 8 & To close bag of the pocket & 4 & & & $40 \%$ \\
\hline 9 & Mounting parmenture & 2 & \multirow{2}{*}{1} & \multirow{2}{*}{ M2 } & $20 \%$ \\
\hline 10 & Topstitch invisible of parmenture & 2 & & & $20 \%$ \\
\hline 11 & To close crowbar back & 2 & \multirow{2}{*}{1} & \multirow{2}{*}{$\mathrm{M} 2$} & $20 \%$ \\
\hline 12 & Pose slanted back & 1 & & & $10 \%$ \\
\hline 13 & Preparation passing & 1 & \multirow{2}{*}{1} & \multirow{2}{*}{ M2 } & $10 \%$ \\
\hline 14 & Stop of the closing of front + spine & 5 & & & $50 \%$ \\
\hline 15 & Assembly cuts up sleeve + slanted & 4 & \multirow{2}{*}{1} & \multirow{2}{*}{$\mathrm{M} 2$} & $40 \%$ \\
\hline 16 & To close sleeve + slanted & 4 & & & $40 \%$ \\
\hline 17 & Assembly shoulders + sides & 3 & 1 & M2 & $30 \%$ \\
\hline 18 & To close middle collar + neck + triquet & 2 & 1 & M2 & $20 \%$ \\
\hline 19 & Colissages neck + invisible surpiquer & 3 & \multirow{3}{*}{1} & \multirow{3}{*}{$\mathrm{M} 2$} & $30 \%$ \\
\hline 20 & Installation neck & 3 & & & $30 \%$ \\
\hline 21 & To close neck & 2 & & & $20 \%$ \\
\hline 22 & Installation watt & 1 & \multirow{2}{*}{1} & \multirow{2}{*}{ M2 } & $10 \%$ \\
\hline 23 & Installation sleeve & 4.5 & & & $45 \%$ \\
\hline 24 & Preparation grasps & 4 & 1 & M2 & $40 \%$ \\
\hline 25 & Topstitch of the ceinture & 4 & 1 & M2 & $40 \%$ \\
\hline 26 & Preparation understudy & 10 & 1 & M2 & $100 \%$ \\
\hline 27 & Hem invisible low sleeve + bottom jacket & 10 & 1 & M3 & $100 \%$ \\
\hline
\end{tabular}




\begin{tabular}{|c|c|c|c|c|c|}
\hline $\mathbf{N}^{\circ}$ & Unit operations & $\begin{array}{c}\text { Operation } \\
\text { time (in min.) }\end{array}$ & $\begin{array}{l}\text { Number of } \\
\text { operators }\end{array}$ & Machines & $\begin{array}{c}\text { Occupation rate } \\
\text { of operation }\end{array}$ \\
\hline 28 & Mounting of epaulet & 2 & \multirow{2}{*}{1} & \multirow{2}{*}{ M2 } & $20 \%$ \\
\hline 29 & Mounting of understudy & 8 & & & $80 \%$ \\
\hline 30 & Ironing of jacket & 2.5 & \multirow{3}{*}{1} & \multirow{3}{*}{ M4 } & $25 \%$ \\
\hline 31 & Ironing installation understudy & 3.5 & & & $35 \%$ \\
\hline 32 & Ironing of collar + understudy & 2.5 & & & $25 \%$ \\
\hline 33 & Pose button + Buttonhole & 8 & 1 & M5 & $80 \%$ \\
\hline 34 & Finish & 8 & 1 & 0 & $80 \%$ \\
\hline 35 & Finished control & 8 & 1 & 0 & $80 \%$ \\
\hline 36 & Packing + cardboard & 8 & 1 & 0 & $80 \%$ \\
\hline
\end{tabular}

Table 2. The transformation operations and the occupation rates

\subsection{FR2: Balancing}

DP2: A qualification of operators, capacity of production and a precedence graph with all the operation times

- Qualification of operators

The steps of jacket assembly have been made by operators supposed to be qualified.

- Precedence graph

The precedence graph of the jacket is exhibited in the Figure 13.

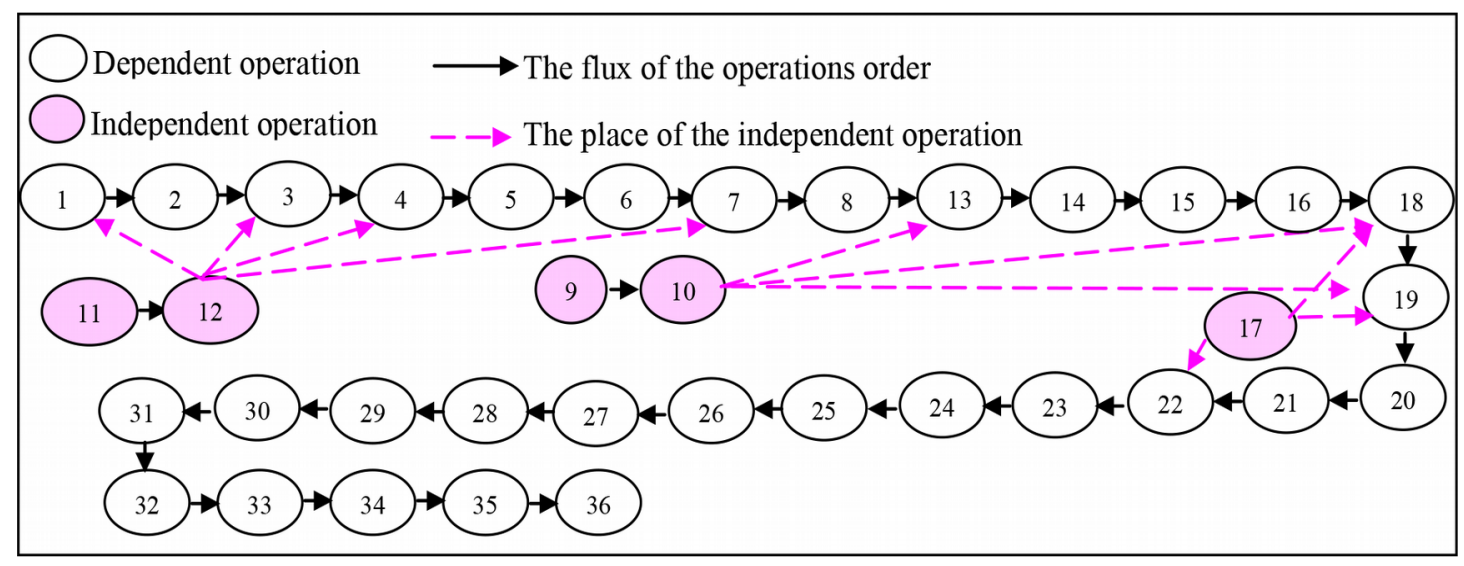

Figure 13. The precedence graph 
- Capacity of production for each operation

Each operation has been timed in Table 2 as using the rotation operator method.

\section{FR21: Partition of operations}

- DP21: Assignment of operations to stations

The classical line-balancing problem (ALB) deals with the affectation of each task to a workstation such as the idle time, which is minimised, and precedence constraints between tasks, which are satisfied for a given cycle time. In this case, only the precedence constraints are taken into account. Then, the assignment of operations to the stations has been made by the occupation rate of every operator, which is calculated by Equation (8). The occupation rate of each operator must not exceed $100 \%$.

$$
\text { Occupation rate }=\frac{\text { Unit period }}{\operatorname{Max}(\text { Unit period })}
$$

In this workshop, the balancing method is based on the combination of operations. Indeed, the assignment of the operations to the stations as indicated in Table 3. As depicted in Table 3, the obtained number of stations is 16 implying the number of operators is 16 because every station is occupied by one operator.

\begin{tabular}{|c|c|c|c|}
\hline $\mathbf{N}^{\circ}$ & $\begin{array}{l}\text { Occupation rate of } \\
\text { every operation }\end{array}$ & $\begin{array}{l}\text { Occupation rate of } \\
\text { every operator }\end{array}$ & Station \\
\hline 1 & $20 \%$ & \multirow{5}{*}{$80 \%$} & \multirow{5}{*}{1} \\
\hline 2 & $10 \%$ & & \\
\hline 3 & $20 \%$ & & \\
\hline 11 & $20 \%$ & & \\
\hline 12 & $10 \%$ & & \\
\hline 4 & $15 \%$ & \multirow{3}{*}{$85 \%$} & \multirow{3}{*}{2} \\
\hline 5 & $40 \%$ & & \\
\hline 6 & $30 \%$ & & \\
\hline 7 & $40 \%$ & \multirow{2}{*}{$80 \%$} & \multirow{2}{*}{3} \\
\hline 8 & $40 \%$ & & \\
\hline 9 & $20 \%$ & \multirow{4}{*}{$100 \%$} & \multirow{4}{*}{4} \\
\hline 10 & $20 \%$ & & \\
\hline 13 & $10 \%$ & & \\
\hline 14 & $50 \%$ & & \\
\hline 15 & $40 \%$ & \multirow{3}{*}{$100 \%$} & \multirow{3}{*}{5} \\
\hline 16 & $40 \%$ & & \\
\hline 18 & $20 \%$ & & \\
\hline
\end{tabular}




\begin{tabular}{|c|c|c|c|}
\hline $\mathbf{N}^{\circ}$ & $\begin{array}{l}\text { Occupation rate of } \\
\text { every operation }\end{array}$ & $\begin{array}{l}\text { Occupation rate of } \\
\text { every operator }\end{array}$ & Station \\
\hline 17 & $30 \%$ & \multirow{3}{*}{$85 \%$} & \multirow{3}{*}{6} \\
\hline 22 & $10 \%$ & & \\
\hline 23 & $45 \%$ & & \\
\hline 19 & $30 \%$ & \multirow{3}{*}{$80 \%$} & \multirow{3}{*}{7} \\
\hline 20 & $30 \%$ & & \\
\hline 21 & $20 \%$ & & \\
\hline 24 & $40 \%$ & \multirow{2}{*}{$80 \%$} & \multirow{2}{*}{8} \\
\hline 25 & $40 \%$ & & \\
\hline 26 & $100 \%$ & $100 \%$ & 9 \\
\hline 27 & $100 \%$ & $100 \%$ & 10 \\
\hline 28 & $20 \%$ & \multirow{2}{*}{$100 \%$} & \multirow{2}{*}{11} \\
\hline 29 & $80 \%$ & & \\
\hline 30 & $25 \%$ & \multirow{3}{*}{$85 \%$} & \multirow{3}{*}{12} \\
\hline 31 & $35 \%$ & & \\
\hline 32 & $25 \%$ & & \\
\hline 33 & $80 \%$ & $80 \%$ & 13 \\
\hline 34 & $80 \%$ & $80 \%$ & 14 \\
\hline 35 & $80 \%$ & $80 \%$ & 15 \\
\hline 36 & $80 \%$ & $80 \%$ & 16 \\
\hline
\end{tabular}

Table 3. Stations

According the Table 3, the precedence graph becomes as the following Figure 14.

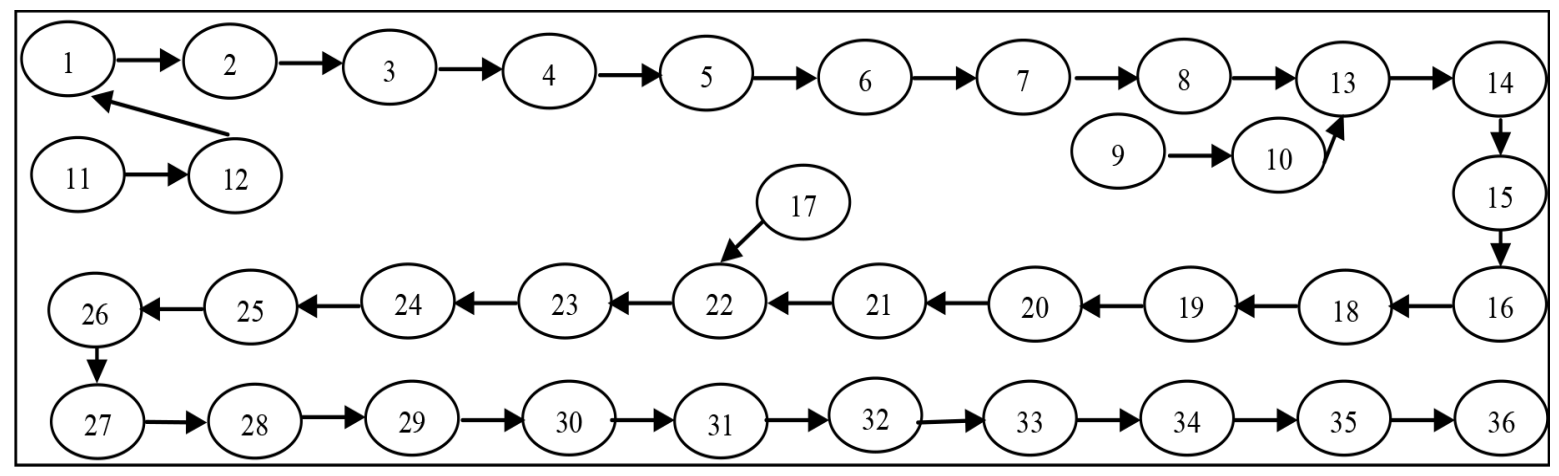

Figure 14. The final precedence graph 
FR22: Sizing of buffers

- DP22: stations and their times

Once the stations are identified then the capacity of each station can be determined as indicated in Table 4. The station time is the sum total of all the processing time of operations which are executed in this station

FR23: Transfer selection

- DP23: Size of buffer

The size of buffer is calculated by the difference between the capacities of two successive stations as it is indicated in Table 4.

It should be noted the capacity of this line is the capacity of bottleneck station: 6.00 pieces/hour $(p / h)$ and the buffer has a small size. In fact, all operators have the same capacity. The operator which troubles the capacity of this workshop has to be replaced by another operator more qualified.

\subsection{FR3: Transport}

DP3: Number of resources

According the Tables 3 and 4, the assembly line needs 16 operators and 13 machines as indicated in Table 5. 


\begin{tabular}{|c|c|c|c|}
\hline Station & $\begin{array}{l}\text { Station time } \\
\text { (in min) }\end{array}$ & $\begin{array}{l}\text { Capacity } \\
(\mathrm{p} / \mathrm{h})\end{array}$ & $\begin{array}{l}\text { The size of buffer } \\
\qquad(\mathrm{p} / \mathrm{h})\end{array}$ \\
\hline 1 & 8 & 7.5 & \multirow[b]{2}{*}{0.5} \\
\hline 2 & 8.5 & 7 & \\
\hline \multirow{2}{*}{3} & 8 & 75 & 0 \\
\hline & & 1.0 & \multirow[t]{2}{*}{1} \\
\hline 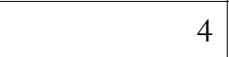 & 9.5 & 6.5 & \\
\hline 5 & 10 & 6 & 0.5 \\
\hline 6 & 8.5 & 7 & 0 \\
\hline 7 & 8 & 7.5 & 0 \\
\hline 8 & 8 & 7.5 & 0 \\
\hline thes & 10 & 6 & 1.5 \\
\hline \multirow{2}{*}{10} & 10 & 6 & 0 \\
\hline & 10 & 0 & \multirow[t]{2}{*}{0} \\
\hline 11 & 10 & 6 & \\
\hline 12 & 8.5 & 7 & 0 \\
\hline 13 & 8 & 7.50 & 0 \\
\hline 14 & 8 & 7.5 & 0 \\
\hline 15 & 8 & 7.5 & 0 \\
\hline 16 & 8 & 7.5 & 0 \\
\hline
\end{tabular}

Table 4. Sizing of buffer

\begin{tabular}{|c|c|r|}
\hline Type of machines & Designation & Number \\
\hline Machine of serging & M1 & 1 \\
\hline Machine simple stitcher & M2 & 1 \\
\hline Machine of hem & M3 & 1 \\
\hline Iron to iron & M4 & 1 \\
\hline Pimply & M5 & \\
\hline
\end{tabular}

Table 5. Number of machines

FR31: Selection of means of transport (nature, tools...)

- DP31: productive flux form

The productive flux is unidirectional with the exception of machines that belong to two lines. Therefore it is necessary to choose a mean of transport that can change its direction easily.

\section{FR32: Determination of parameters of transport}

- DP32: Nature, means and tools of transport

This type of assembly line needs the box as tool of transport and the operator as mean of transport. 


\subsection{FR4: Configuration}

DP4: The parameter of transport and line form

The line has two parameters of transport which are the lot of the transport size and the capacity of transport. The size of transport varies according to the order of product (max: 50 pieces) and the transport time of operator between two workstations is 60 seconds then the capacity of transport is 3600 pieces/hour.

According to the process of jacket manufacturing example, the stations are organized linearly with the exception of stations that belong to the two lines such as stations: 3, 10, 13, 14, 15 and 16. The configuration of the line can be represented as indicated in Figure 15.

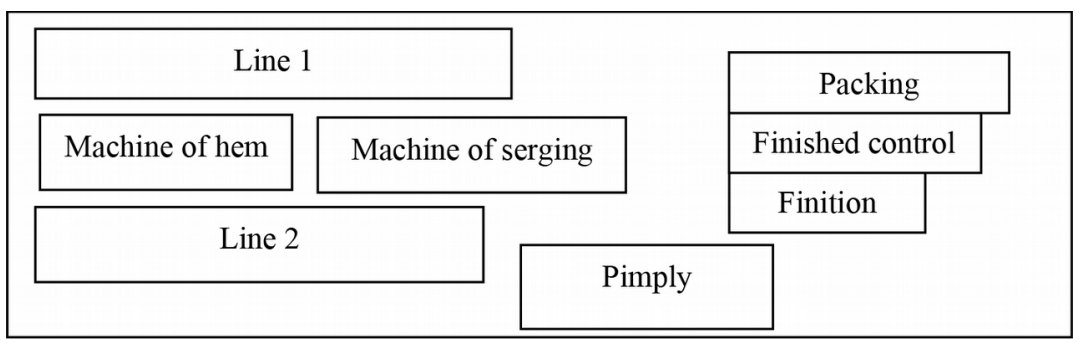

Figure 15. Line configuration

FR41: Implantation (or suppressions) machines, equipments, etc.

- DP41: Production capacity and a line form

According to the transport and production capacity and a line form, machines of hem and serging will be implanted to the centre of the shop between the two lines to facilitate the handling for the two machines.

FR42: Modification of organisation (operations, tasks, operators)

- DP42: Disposition of stations

According to all the parameters obtained, the stations are organized as indicated in the Figure 15 to facilitate the handling between two lines and to minimize the cycle time of production. 


\subsection{FR5: Validation of Approach}

DP5: All selected necessary parameters

The necessary parameters are selected from Tables 3, 4 and 5.

\section{FR51: Modelling and validation}

- DP51: The parameter of modelling and the type of productive flux

According to all these parameters, the new assembly line is designed as indicated in Figure 16.

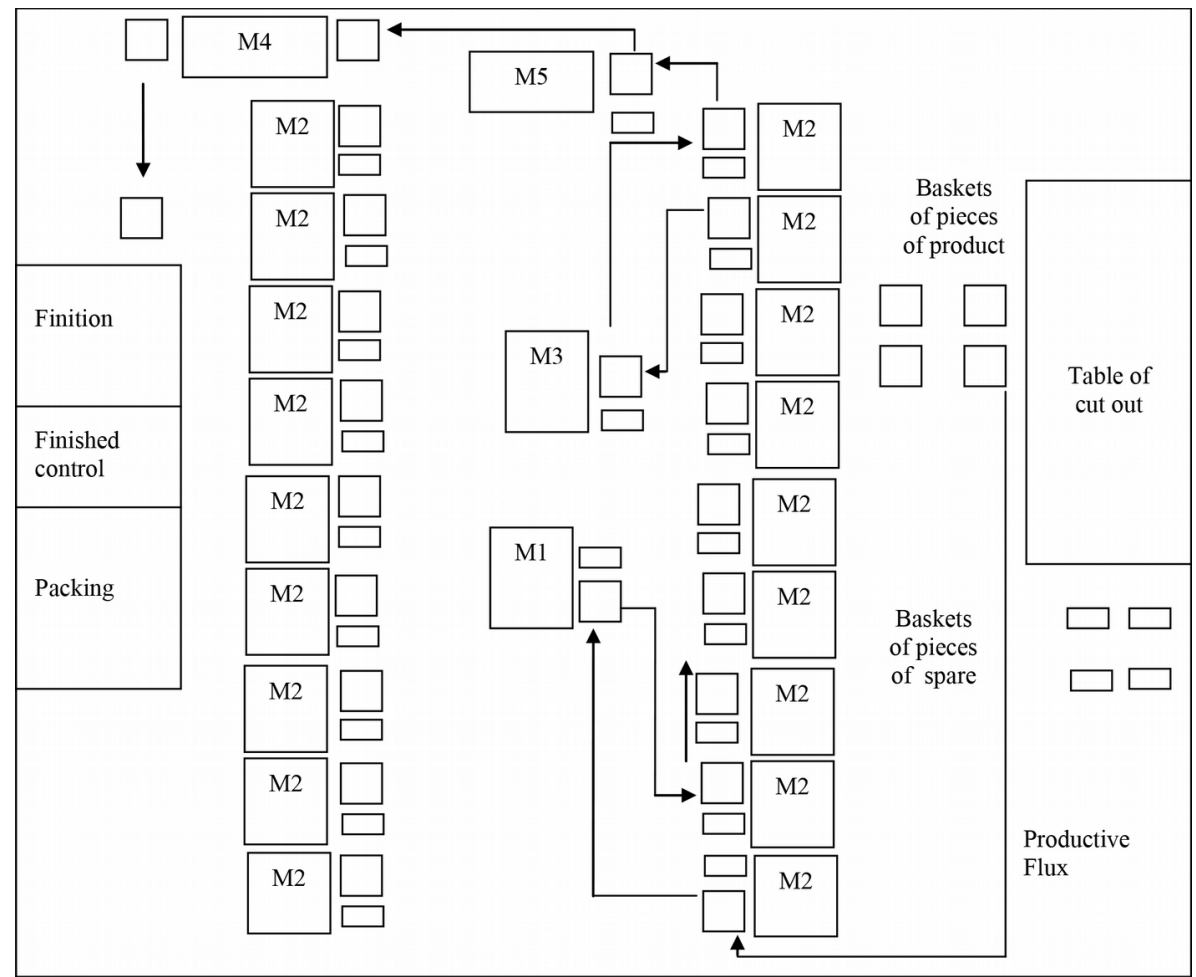

Figure 16. Productive flux of the assembly line

\section{FR52: Development of a computer model of simulation and validation}

The software Arena is used, which is a powerful tool for decision support to model and simulate manufacturing system design. For validation of the obtained line, a graphical interface that provides visual support to model is used and a found production line design is simulated. 
- DP52: Condition of running with data and variables of model

The data base must enter of the assembly line in the menu run set up such as number of replication (one replication) and the hours per day (8 hours/day) of line. The stopping criterion can be the production quantity or residence time and the time between arrivals is a data ( 3 minutes for this example). In this case, the production quantity is fixed at 100 pieces.

\section{FR53: Verification of model}

The new assembly line is modelled on the Arena software to extricate the indicators of performance. In this work, an indicator of comparison (IC) is used between new assembly line values (NLV) and initial line values (ILV). IC is expressed as the following Equation (9):

$$
I C=\frac{I L V-N L V}{I L V}
$$

- DP53: The indicators of performances

If the Arena software is used, the verification will be established by the comparison between indicators of performance of the new assembly line and indicators of performance of the initial assembly line. The obtained performance indicators of two lines by simulation are indicated in the following Tables 6, 7 and 8 .

\begin{tabular}{|l|r|r|}
\hline \multicolumn{1}{|c|}{ Line parameters (in min) } & Ancient assembly line & New assembly line \\
\hline Residence time & 1392 & 1144 \\
\hline Transfer time & 15 & 15 \\
\hline Waiting time & 470 & 346 \\
\hline Work in process & 44.8 & 43 \\
\hline
\end{tabular}

Table 6. The assembly line results

The experimental results of the proposed process are summarised in Table 7

According to Table 7, there exists the reduction of number of operators by IC $=27,27 \%$ and the number of machines by IC $=31.57 \%$. Consequently, the resources cost can be optimized (humans and machines). The residence time, waiting time and waiting in process (pieces number pending in line) are taken also indicators of performance of line. We notice in Table 7 that these indicators of new line decrease by IC $=18 \%$ for the residence time, by IC $=26 \%$ for the waiting time and by 
IC $=5 \%$ for the waiting in process. These results show that the cycle time of production is optimized.

\begin{tabular}{|l|r|r|r|}
\hline \multicolumn{1}{|c|}{ Parameters } & Initial line & New line & \multicolumn{2}{c|}{ IC } \\
\hline Number of operators & 22 & 16 & $27.27 \%$ \\
\hline Number of machines & 19 & 13 & $31.57 \%$ \\
\hline Residence time & 1392 & 1144 & $18 \%$ \\
\hline Transfer time & 15 & 15 & 0 \\
\hline Waiting time & 470 & 346 & $26 \%$ \\
\hline Work in process & 44.8 & 43 & $5 \%$ \\
\hline
\end{tabular}

Table 7. Comparison between initial line and new line

In order to confirm the balancing of the obtained line, the occupation rate of every station is calculated. The results of Table 8 exhibited that the new assembly line is more balanced than the initial line because the occupation rates of the new line are important and nearly equal.

\begin{tabular}{|c|c|c|}
\hline Usage & Ancient assembly line & New assembly line \\
\hline Station & Occupation rate & Occupation rate \\
\hline 1 & 0.58 & 0.71 \\
\hline 2 & 0.62 & 0.75 \\
\hline 3 & 0.58 & 0.71 \\
\hline 4 & 0.51 & 0.84 \\
\hline 5 & 0.58 & 0.89 \\
\hline 6 & 0.91 & 0.75 \\
\hline 7 & 0.62 & 0.71 \\
\hline 8 & 0.58 & 0.71 \\
\hline 9 & 0.73 & 0.89 \\
\hline 10 & 0.73 & 0.89 \\
\hline 11 & 0.73 & 0.89 \\
\hline 12 & 0.55 & 0.75 \\
\hline 13 & 0.59 & 0.71 \\
\hline 14 & 0.59 & 0.71 \\
\hline 15 & 0.59 & 0.71 \\
\hline 16 & 0.59 & 0.71 \\
\hline
\end{tabular}

Table 8 . The occupation rate of station 


\section{Conclusion}

In this work, an approach is developed to obtain a global process for the production line design. First, a SADT method is used to assure the satisfaction of the two axioms to find the better design. Second, the hierarchical decomposition of $\mathrm{AD}$ is deduced from SADT method to construct the model of approach and the designs matrices. Third, this approach is applied on manufacturing example for validation the proposed design process. Then, the obtained and initial lines are modelled and simulated in Software Arena to determine their performance indicators. Finally, the results show that the obtained line by the proposed process is more optimized and balanced than the initial line through comparing the performance indicators. According to this design method, the number of operators can be optimized, the cycle time can be minimized and the obtained assembly line is more balanced than the initial line. In addition, this approach can be applied to other types of manufacturing examples, as assembly line of tap gas to prove that the proposed model of design is a generic model. It can be applied to any other assembly line that presents our design hypotheses. Furthermore, the proposed process of design can be enriched by adding other hypotheses (on the maintenance strategies, availability of operators, etc.) or fixing constraints on the speed of machines, the cost of resources, operator skills, among others. According to theses propositions, the proposed process can be redeveloped by having another sub levels and details of assembly line design.

\section{References}

Albano, L.D., \& Suh, N.P. (1992). Axiomatic approach to structural design. Research in Engineering Design, 4(3), 171-183. https://doi.org/10.1007/BF01607945

Arinez, J.F., \& Cochran, D.S. (2000). An equipment design approach to achieve production system design requirements. Proc. of 33rd CIRP Int'l Seminar on Mfg. Systems. Stockholm.

Asar, K., \& Andrew, J. (2001). A Knowledge based design methodology for manufacturing assembly lines. Computerల industrial engineering, 41(4), 441-467.

Dolgui, A. (2001). Automated Production Line Design (Preface for the Special Track). Management and Control of Production and Logistics: A Proceedings Volume. Pergamon, Elsevier Science.

Dolgui, A., \& Ihnatsenka, I. (2009). Branch and bound algorithm for a transfer line design problem: Stations with sequentially activated multi-spindle heads. European J. of Operation Research, 197(3), 1119-1132. https://doi.org/10.1016/j.ejor.2008.03.028 
Essafi, M., Delorme, X., Dolgui, A., \& Guschinskaya, O. (2009). A MIP approach for balancing transfer line with complex industrial constraints. Computers \& Industrial Engineering, 58(3), 393-400. https://doi.org/10.1016/j.cie.2009.04.009

Ferrer, I., Rios, J., \& Ciur, J. (2009). An approach to integrate manufacturing process, information in part design phases. Journal of Materials Processing Technology, 209(4), 2085-2091.

https://doi.org/10.1016/j.jmatprotec.2008.05.009

Gebala, D.A., \& Suh, N.P. (1992). An application of axiomatic design. Research in Engineering Design, 3(3), 149-162. https://doi.org/10.1007/BF01580517

Graves, S.C., \& Lamar, B.W. (1983). An integer programming procedure for assembly system design problems. Operation Research, 31(3), 522-545. https://doi.org/10.1287/opre.31.3.522

Guschinskaya, O., Dolgui, A., Guschinsky, N., \& Levin, G.(2007). A heuristic multi-start decomposition approach for optimal design of serial machining lines. European J. of Operation Research, 189(3), 902-913. https://doi.org/10.1016/j.ejor.2006.03.072

Hachicha, W., Masmoudi, F., \& Haddar, M. (2008). Combining Axiomatic Design and Designed Experiments for cellular manufacturing systems design framework. Int. J. of Agile System and Management, 3(3/4), 306-319. https://doi.org/10.1504/IJASM.2008.021215

Hayes, RH., \& Wheelwright, S.C. (1979). Link manufacturing process and product lifecycle's. Harvard Business Review.

Houshmand, M., \& Jamshidnezhad, B. (2006). An extended model of design process of lean production systems bymeans of process variables. Robotics and Computer-Integrated Manufacturing, 22(1), 1-16. https://doi.org/10.1016/j.rcim.2005.01.004

Kulak, O., Cebi, S., \& Kahraman, C. (2010). Applications of axiomatic design principles: A literature review. Expert Systems with Applications, 37(9), 6705-6717. https://doi.org/10.1016/j.eswa.2010.03.061

Kuo, R.J., \& Yang, C.Y. (2011).Simulation optimization using particle swarm optimization algorithm with application to assembly line design. Applied Soft Computing, 11(1), 605-613.

https://doi.org/10.1016/j.asoc.2009.12.020

Lan, C. (2007). The design of multiple production lines under deadline constraint. Int. J. Production Economics, 106(1), 191-203. https://doi.org/10.1016/j.ijpe.2006.05.012 
Lenz, E., Rubinovitz, J., \& Bukchin, J. (1993). RALB - A Heuristic Algorithm for Design and Balancing of Robotic Assembly Lines. Annals of the CIRP, 42(1), 497-500. https://doi.org/10.1016/S00078506(07)62494-9

Lindkvist, L., \& Soderberk, R. (2003). Computer-aided tolerance chain and stability analysis. Journal of Engineering Design, 14(1), 17-39. https://doi.org/10.1080/0954482031000078117

McMullen, P.R., \& Frazier, G.V. (1998). Using simulated annealing to solve a multi-objective assembly line balancing problem with parallel stations. Int. J. of Production Research, 36(10), 2717-2741. https://doi.org/10.1080/002075498192454

Miralles, C., García-Sabater, JP., Andrés, C., \& Cardós, M. (2008). Branch and bound procedures for solving the assembly line worker assignment and balancing problem. Application to sheltered work centres for disabled. Discrete Applied Mathematics, 156(3), 352-367. https://doi.org/10.1016/j.dam.2005.12.012

Nada, O.A., Elmaraghy, H.A., \& W.H. Elmaraghy (2006). Quality Prediction in Manufacturing System Design. Journal of Manufacturing systems, 25(3), 153-171. https://doi.org/10.1016/S0278-6125(08)00002-2

National Academy of Engineering (2002). Approaches to Improve Engineering Design. http://books.nap.edu/books/NI000469/html/R1.html (Accessed: June 2003).

Nazarian, E., \& Ko, J. (2013). Robust manufacturing line design with controlled moderate robustness in bottleneck buffer time to manage stochastic inter-task times. Journal of Manufacturing Systems, 32(2), 382-391. https://doi.org/10.1016/j.jmsy.2012.12.005

Nourmohammadia., A., Zandiehb., M., \& Tavakkoli-Moghaddamca, R. (2013). An imperialist competitive algorithm for multi-objective U-type assembly line design. Journal of Computational Science, 5(4), 393-400. https://doi.org/10.1016/j.jocs.2012.09.001

Rekiek, B., Dolgui, A., Delchambre, A., \& Bratcu, A. (2002). State of art of optimization methods for assembly line design. Annual Reviews in Control, 26(2), 163-174. https://doi.org/10.1016/S1367-5788(02)00027-5

Schnetzler, M.J., Sennheiser, A., \& Schonsleben, P. (2007). A decomposition-based approach for the development of a supply chain strategy. International Journal of Production Economics, 105(1), 21-42. https://doi.org/10.1016/j.ijpe.2006.02.004

Scholl, A., Fliedner, M., \& Boysen, N. (2011). ABSALOM: Balancing assembly lines with assignment restrictions. European Journal of Operational Research, 200(3), 688-701. https://doi.org/10.1016/j.ejor.2009.01.049

Suh, N.P. (1990). The Principles of Design. New York, NY: Oxford University Press. 
Suh, N.P.(1995). Designing-in of quality through axiomatic design. IEEE Transactions on Reliability, 44(2), 256-264. https://doi.org/10.1109/24.387380

Suh N.P. (2001). Axiomatic Design-Advances and Applications. New York, NY: Oxford University Press.

Taha, Z., Soewardi, H., \& Dawal, S.Z.M. (2014). Axiomatic design principles in analysing the ergonomics design parameter of a virtual environment. International Journal of Industrial Ergonomics, 44 (3), 368-373. https://doi.org/10.1016/j.ergon.2013.11.007

Tate, D.A. (1999). Roadmap for decomposition: Activities, theories, and tools for system design. PhD thesis. Cambridge, MA: Massachusetts Institute of Technology.

Xu, Z., Ko, J., Cochran, D.J., \& Jung, M. (2012). Design of assembly lines with the concurrent consideration of productivity and upper extremity musculoskeletal disorders using linear models. Computers \& Industrial Engineering, 62(2), 431-441. https://doi.org/10.1016/j.cie.2011.10.008

Journal of Industrial Engineering and Management, 2017 (www.jiem.org)

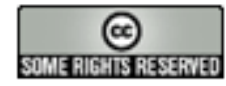

Article's contents are provided on an Attribution-Non Commercial 3.0 Creative commons license. Readers are allowed to copy, distribute and communicate article's contents, provided the author's and Journal of Industrial Engineering and Management's names are included. It must not be used for commercial purposes. To see the complete license contents, please visit http://creativecommons.org/licenses/by-nc/3.0/. 